\title{
A study on the measurement method of effect for healthcare-safety-education
}

\author{
Takeyuki Goto*1 ${ }^{*}$ Masahiko Munechika ${ }^{1}$, Chisato Kajihara ${ }^{1}$ \\ 1. Waseda University: 14F-12, Annex\#51, 3-4-1, Okubo, Shinjuku-ku, Tokyo, Japan, 169-8555 \\ *contact author's e-mail address: noelgot326@ruri.waseda.jp
}

\begin{abstract}
:
Medical technology has been consistently improving in recent years. With that, people are more concerned with medial safety and its quality. In medical service provided by hospitals, quality is greatly influenced by human knowledge and skills. Therefore, it is fundamental to improve these factors. Actually, at many hospitals, medical safety education is provided to employees. To conduct more efficient education, the effectiveness of the education must be evaluated, and the specific contents must be revised after its administration. It is said that effects of an education can be evaluated in terms of learning (knowledge and skill) and the degree of behavior modification and results. In evaluation, we should begin by evaluating learning, and then move to behavior and results. However, the methodology for measuring these has not been established. In this study, we analyzed the long-term findings in a hospital and implemented an evaluation model for medical safety education. Further, we designed the effectiveness measurement tool based on that model. We then propose a method for measuring the effects of healthcare safety education. Using this method, medical workers can evaluate students' learning free of bias and extensive work after providing education. In addition, they can review the contents of education and provide sufficient feedback on the test results to students.
\end{abstract}

\section{Keywords}

Educational evaluation, Healthcare Safety, Behavior modification, Skill, Knowledge

\section{Introduction}

Delivering safe medical service is an essential aspect of health care. The quality of medical services is influenced by human knowledge and skills. Therefore, many Japanese hospitals conduct educational programs on medical safety for their employees. Such programs help students acquire knowledge (i.e., gaining an understanding about a concept or a term) and skills (i.e., the ability to apply their knowledge and techniques). However, it is also important that the students are able to utilize the knowledge and skills that they learn in the workplace. Therefore, to examine the effectiveness of an educational program, it is necessary to assess the behavioral changes it brings about (changes in actions on the job). However, due to the lack of evaluation methods, it is not currently possible to review the contents of the program and provide sufficient feedback to the students. Therefore, in the present study, we propose a method to evaluate educational programs for healthcare safety.

\section{Previous research and approach of this study}

\subsection{Previous research}

Tsutsumi et al. assume that there is insufficient knowledge on technology for measuring the effects of education. Further, they state that it is difficult to measure effects of education in a given field, as deep, specialized knowledge, such as the knowledge of statistics used for ascertaining knowledge and reliability of a learning theme, is necessary. The situation is similar with medical safety education.

To grasp the present conditions of the measurement of education effects in medical safety education, we conducted an actuary investigation hearing regarding impeller medical care security of 10 hospitals, which participated in a 2013 meeting for a study on quality and security of first-aid medical care. Ultimately, the 
hospitals indicated that, ““'We conducted medical safety education, but evaluation is a problem.” Further, they said "We did the understanding degree investigation, but we wish we could evaluate the action transformation."From this result, at many hospitals, medical safety education is carried out without measurement of its effect, and thus, a review of the education and feedback from students attending the lecture were lacking.

Regarding a trend in measuring education effects among general companies, according to the Association of Training and Development (ATD, formerly ASTD), the models that attracted attention from the 1990s through the 2000s were the four phases of Kirkpatrick's model , the return on investment (ROI) model of Philips , and the success case method .Above all, Phillips' ROI model (cf. Table 1) is a widely used effect measurement model. However, it is an inflection example of these models, and the concrete methodology is not shown. It may be said that the company builds an evaluation method in accord with its training methods while receiving the support of the consulting company.

Table 1. The five-level framework suggested by Phillips

\begin{tabular}{|l|l|l|}
\hline Level & Impact of Education & Details \\
\hline $\mathbf{1}$ & Reaction and Planned Action & Reaction of the student to attending a lecture \\
\hline $\mathbf{2}$ & Learning & Knowledge and skills \\
\hline $\mathbf{3}$ & Job Application & Changes in actions on the job \\
\hline $\mathbf{4}$ & Business Result & Performance and result of the work \\
\hline $\mathbf{5}$ & Return on Investment & Effect of the investment \\
\hline
\end{tabular}

As a result of having investigated a study in conjunction with medical safety education, we determined that many studies have been conducted in accordance with the medical safety education program, and there are few studies on effect measurement. Regarding the study of the medical safety education program, for example, Kajihara defined education as the fostering talented individuals who can practice medical safety management in terms of medical safety education. She derived the medical safety education items that should be explained by education programs with reference to a way of thinking and the activity of quality management systems (QMSs) in the industry, and she arranged these items in a table. In this way, each hospital was able to establish and review the medical safety education system.

As in other studies, there is a standard text development for the promotion of medical safety, a study on simulation education , a study on policies toward security awareness in the healthcare setting, and so on. It may be said that various studies have been conducted on enforcement methods of medical safety education.

Regarding the study of the effectiveness of medical safety education, we include a study on the measurement of the medical safety consciousness and a study of the attitude survey with regard to specific training. For example, Takemura et al. indicated that the tools that evaluated medical safety awareness, such as the Safety Attitudes Questionnaire or the Hospital Survey on Patient Safety Culture, were developed mainly in the United States. Further, they utilized those tools and observed variability of medical safety consciousness and subsequently analyzed this variability.In addition, Morinaga et al. suggested a questionnaire survey method as a measure of the effectiveness of a medical safety self-prevention training program from a psychological viewpoint. In addition, Goto et al. discussed the methodology for effect measurement at level 2 ("Learning and knowledge" in Table 1).

The purpose of this study was to establish the method for measuring effectiveness of a medical safety education and to improve the educational program and the feedback provided to students attending the lecture. It may be said that the tool that can be used as an attitude survey of the medical safety culture can help to generalize to the degree of recognition of medical security, and to evaluate this as well. However, using the result of the generalization evaluation, it is difficult to improve the educational program and to perform the feedback in detail for the students attending lectures. In addition, most questionnaire surveys that measure effective training methods include an unclear development process. Therefore, it is difficult to determine whether a logical technique for developing questionnaire items was used. In addition, we cannot ensure the reliability or validity of the evaluation.Moreover, in Goto et al, only level 2 in Table 1 is considered to examine the measurement of the method's effectiveness. The purpose of our study is to introduce medical safety education and to ensure the security of patients, and thus it is not solely intended to acquire knowledge.

We should grasp all the effects of Table 1, levels 1-5 to achieve the final purpose, namely, ensuring patient security. To obtain such an effect, it is desirable to improve the education curriculum and contents.In addition, 
not only did we seek to improve education, but also we should provide appropriate feedback and manage motivation. To construct an environment in which education contents can be effectively used is essential for students attending the lectures.

Our aim then, based on the above-mentioned investigation, is as follows, it is useful for a hospital which conducts medical care safety education, there should be a method to improve feedback towards improving the program, and students attending a lecture of the educational program should conduct this feedback after performing the measurement of the effectiveness of the medical safety education.

\subsection{Approach of this study}

In this study, we examined the measurement method based on two educational programs. The Process Oriented Analysis Method (POAM) and Kiken Yochi Training (KYT) were carried out in Hospital A and B, respectively. We first examined the effectiveness of "Reaction \& Planned Action "and "Learning", and investigated the opinion of the students who attended a lecture. Specifically, we explored the students' opinions on their present knowledge and acquisition level, as affected by their participation in the POAM program. Based on those results, we then examined the aim of a program with reference to the action model suggested by Marzano et al. and make the evaluation criteria of the degree of action transformation. Subsequently, we developed a questionnaire based on the evaluation criteria and examined the effectiveness of "Job Application". Based on these findings, in the present paper, We propose a method to examine the effectiveness of medical safety education.

\section{Examining the effectiveness of the proposed method to evaluate medical safety education}

\section{3 .1 The measurement and attitude survey on Level 1 and 2}

We examined the effectiveness of Level 1 and 2 using the method proposed by Goto and others . Thus, we evaluated the level of understanding of 30 student nurses who attended a lecture on POAM that was carried out with an X-disease ridge of Hospital A, in June 2013. In addition, we attempted to introduce POAM into the whole ward in the X-disease ridge, within one year, during 2013. To examine Level 1, we used a form to evaluate the degree of understanding of the course contents in students attending a lecture, their degree of interest, and their evaluations of how the lectures were conducted, in five phases each. As for the evaluation of the degree of understanding for Level 2, we addressed two aspects: knowledge and skills. Thus, we evaluated their degree of acquisition of skills on a five-point scale, and that of knowledge on a 14-point scale, where a total score of 19 points indicated a perfect score. Similar to the evaluation of Level 2 was conducted thrice, in June, September, and December, after the completion of the program. The findings from the evaluation of Level 1 are presented in Table 2. Figure 1 presents findings of the evaluation of Level 2 for six people, to illustrate two or three.

Table 2. Results from the evaluation of Level 1

\begin{tabular}{|l|c|c|c|c|}
\hline & Intelligibility & Usefulness & $\begin{array}{c}\text { Degree of } \\
\text { interest }\end{array}$ & $\begin{array}{c}\text { How the lectures } \\
\text { were conducted }\end{array}$ \\
\hline Student a & 4 & 4 & 4 & 4 \\
\hline Student b & 4 & 4 & 5 & 5 \\
\hline Student c & 3 & 4 & 4 & 4 \\
\hline Student d & 4 & 4 & 5 & 3 \\
\hline Student e & 4 & 3 & 4 & 4 \\
\hline Student f & 4 & 4 & 5 & 5 \\
\hline
\end{tabular}




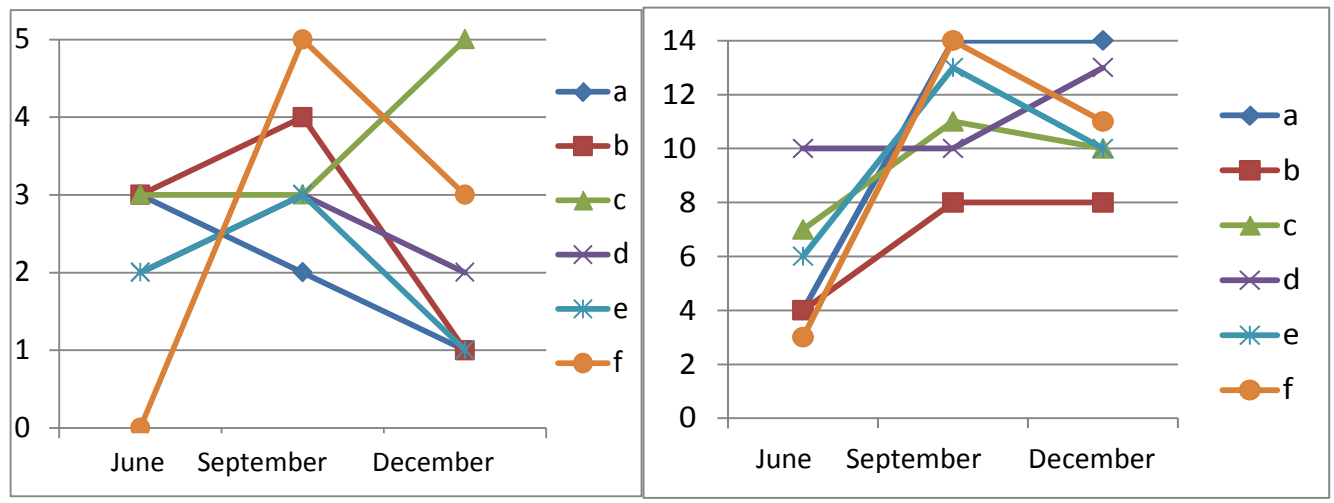

Figure 1. Results from the evaluation of Level 2(Left: Knowledge; Right: Skill)

As shown in Table2 the degree of intelligibility, usefulness and degree of interest tended to be high, perhaps because the evaluation was conducted soon after the program. Further, as observed in Figure 1, the evaluation scores improved in September, as compared to June, which indicates that most of the students attending the lectures implemented positively the POAM in the ward. On the other hand, the scores decreased in December. To explore this further, we obtained the opinion of the manager of the X-disease ridge to examine onsite activity. In addition, we interviewed a student who attended the lectures and provided the highest score in the evaluation of Level 2. We found that their consciousness changed by education. It is thought that a change in the consciousness, such as in the degree of interest in the student attending a lecture, or the degree of usefulness, influences the degree of acquisition and the degree to which learning is transformed into action.

\subsection{Examining the method to evaluate Level 3}

\section{2.1 Examining the use of the action model in education}

Based on the findings presented in Section 3.1, we hypothesized that a change in the consciousness of the student attending a lecture influenced an action by affecting the degree of acquisition. This suggests that, to evaluate a program that aims to change the consciousness of the student attending a lecture, it is necessary to measure the degree to which the learning is transformed into action, thus implying the need to develop a method to evaluate the same. Therefore, I utilized the action model suggested by Marzano et al. (see Figure 2).

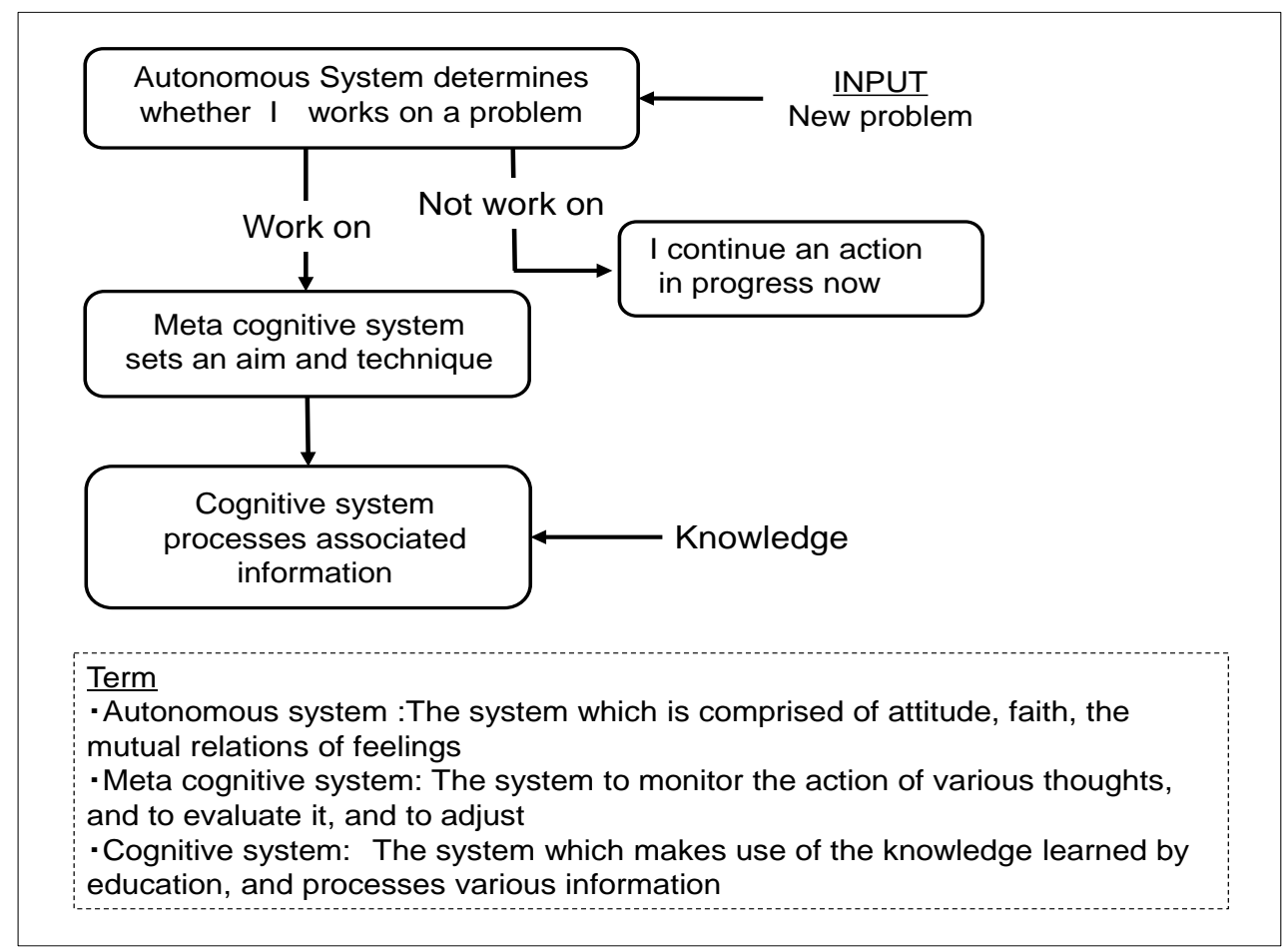

Figure 2. The action model suggested by Marzano and others 
In this model, it is suggested that when a student who attends a lecture faces a new problem, the autonomous system closely evaluates the importance of the problem, the feelings, and the effectiveness of education . If it is judged that one should work on a problem, the meta-cognitive system sets an aim for the solution of a problem while the cognitive system manages the knowledge derived from the contents of the educational program, which is saved in the student's memory. Section 3.1 revealed that the change in the consciousness occurs during the process of education, as well as during onsite activity after the completion of the program.

Therefore, it is desirable to evaluate Level 3 based on the autonomous system before and after the education, to measure the degree to which the learning is transformed into action and the time of this transformation. Thus, we used the change due to education in the consciousness of the student attending a lecture as the goal or end point of the action model, and evaluated the process of change by using the action model in the beginning and ending. The model that we used in the present study is presented in Figure 3.

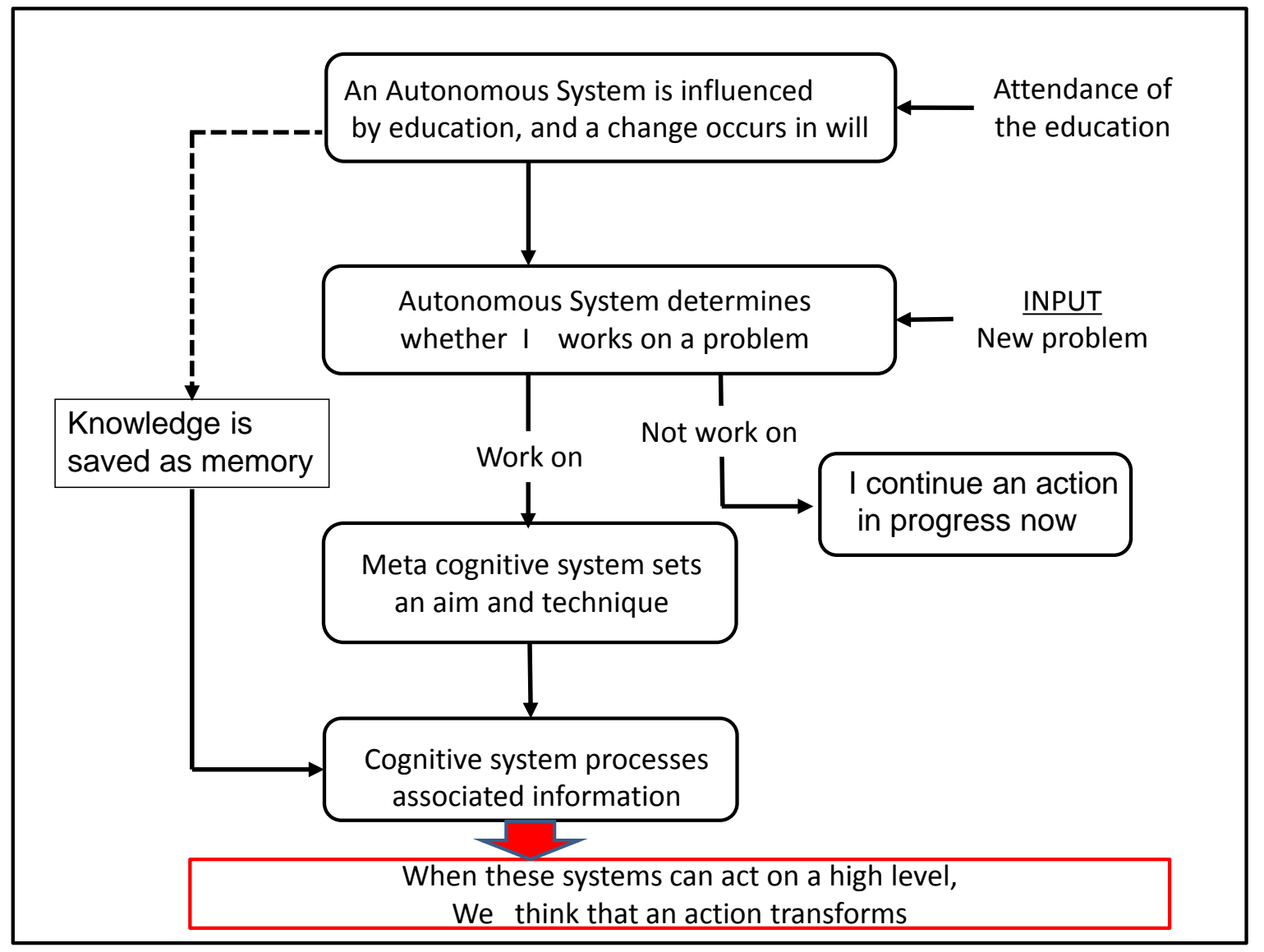

Figure 3. The action model used in this study

On attending an educational program, an autonomous system simultaneously undergoes changes and saves the knowledge to memory. When a student decides to work on a problem based on the autonomous system, she establishes an aim, and the cognitive system processes the problem. It is believed that this process leads to a change in the action. Thus, based on this model, for an action to be transformed, it is necessary for the following requirements to be met: (a)The student's will to attend a lecture increases after education.

(b)An aim and a plan need to be established.

(c)The student can handle a new problem onsite.

Thus, if these three requirements are met, there may be a high level of action transformation. Therefore, in order to examine the level of transformation in an action, we studied the level of these requirements.

\section{2.2 Examining the evaluation criteria}

Based on the action model explained in Section 3.2.1, we determined that bringing about a transformation in 
the action is the goal of POAM. Further, we specified the content of the knowledge to be provided through the educational program and the mental procedure involved, and explained the content of each system in the action model. These results are presented in Table 3.

Table 3. Goal of the POAM

\begin{tabular}{|c|c|c|}
\hline $\begin{array}{c}\text { Aim } \\
\text { classification }\end{array}$ & Contents & Evaluation item \\
\hline \multirow{4}{*}{$\begin{array}{l}\text { Autonomous } \\
\text { system }\end{array}$} & $\begin{array}{l}\text { Examining the } \\
\text { importance }\end{array}$ & $\begin{array}{l}\text { I realize that it is important to analyze an accident in terms of the } \\
\text { process. }\end{array}$ \\
\hline & $\begin{array}{l}\text { Examining the } \\
\text { effectiveness }\end{array}$ & I believe that I can apply the POAM \\
\hline & $\begin{array}{l}\text { Examining one's } \\
\text { feelings }\end{array}$ & I have affirmative feelings about the POAM \\
\hline & $\begin{array}{l}\text { Examining one's } \\
\text { will }\end{array}$ & I am willing to use the POAM \\
\hline \multirow{4}{*}{ Meta-cognition } & Realizing the aim & I can determine an aim to utilize the POAM \\
\hline & $\begin{array}{l}\text { Process } \\
\text { monitoring }\end{array}$ & $\begin{array}{l}\text { When I utilize the POAM, I can understand for how long an aim is } \\
\text { accomplished }\end{array}$ \\
\hline & $\begin{array}{l}\text { Monitoring the } \\
\text { accuracy }\end{array}$ & I can articulate when I am confused about the POAM \\
\hline & $\begin{array}{l}\text { Accurate } \\
\text { monitoring }\end{array}$ & $\begin{array}{l}\text { I can demonstrate, with evidence, for how long I have known to use } \\
\text { the POAM }\end{array}$ \\
\hline \multirow{4}{*}{$\begin{array}{l}\text { Application of } \\
\text { the knowledge }\end{array}$} & Decision making & I can make decision using the POAM \\
\hline & $\begin{array}{l}\text { Solution to the } \\
\text { problem }\end{array}$ & I can solve the problem using the POAM \\
\hline & Experiment & I can develop a hypothesis using the POAM and can inspect it \\
\hline & Investigation & I can use the POAM for investigating a future event, based on the past \\
\hline \multirow{5}{*}{ Analysis } & Comparison & $\begin{array}{l}\text { I can identify the differences between the POAM and other analysis } \\
\text { techniques }\end{array}$ \\
\hline & Classification & I can classify the POAM in the technique used to analyze the accident \\
\hline & Error analysis & $\begin{array}{l}\text { I can compare the POAM by a thinking that another person showed } \\
\text { and can point out a mistake }\end{array}$ \\
\hline & Generalization & Based on my learning, I can speak about the POAM \\
\hline & Realization & $\begin{array}{l}\text { I can generate about the POAM and, under a certain condition,I can } \\
\text { provide evidence for the same }\end{array}$ \\
\hline \multirow[t]{2}{*}{ Understanding } & Unification & $\begin{array}{l}\text { I can compare the characteristic of the POAM by that when I do not } \\
\text { use the POAM }\end{array}$ \\
\hline & Symbolization & I can depict a main element of the POAM in a figure \\
\hline \multirow{3}{*}{ Extraction } & Recognition & $\begin{array}{l}\text { I can check whether the words that it is process-oriented exactly or } \\
\text { not. }\end{array}$ \\
\hline & Reproduction & I can explain the purpose of the POAM \\
\hline & Practice & I can apply the analysis procedure suggested in the POAM \\
\hline
\end{tabular}

For example, the importance, effectiveness, feelings, and will are examined in the autonomous system, and it is desirable that they are affirmative evaluations. Thus, I could derive four outcomes for each aim. This process can also be applied to other items. 


\section{3 .2.3 Design of the survey questionnaire}

We designed a survey questionnaire to evaluate the evaluation criterias we derived. This evaluation was conducted by the students who attended a lecture.

Table 4. List of items in the questionnaire on the POAM

\begin{tabular}{|l|l|}
\hline Q1 & I realize that it is important that I practice a process point in accident analysis. \\
\hline Q2 & I am sure that I can utilize the POAM well. \\
\hline Q3 & I am aware of the weak points in the analysis technique of the POAM. \\
\hline Q4 & I usually willingly use the POAM for analysis. \\
\hline Q5 & I set an aim for myself, to utilize the POAM, and make a plan for the same. \\
\hline Q6 & When I analyze using the POAM, I can understand how my aim was accomplished. \\
\hline Q7 & With reference to the POAM, I can indicate the contents that I understand, and those I do not. \\
\hline Q8 & I can make a decision by thinking things by a process \\
\hline Q9 & I can solve a problem by improving the way I fulfill everyday duties. \\
\hline Q10 & I can indicate the errors in the analysis conducted by another person, and modify them. \\
\hline Q11 & I can express my thoughts about the POAM. \\
\hline Q12 & I can explain a purpose and a process point of the POAM to another person. \\
\hline Q13 & I can carry out the POAM according to an analysis procedure. \\
\hline
\end{tabular}

With reference to the items of this questionnaire, based on the inputs of the medical safety manager of Hospital A, we created an item each, on will, goal setting, and the degree of understanding. We made each evaluation item to evaluate with five phases. We carry out an evaluation using this item.

\subsubsection{Design of the evaluation standard list}

We constructed an evaluation standard list to evaluate the on-site influence of education contents. It is a characteristic of medical safety education that penetration activities are carried out in hospitals to consolidate education contents to students attending lectures after education. Thus, the evaluator can collect activity results as an evaluation document, and it may be said that this leads to the evaluation of the on-site utilization to evaluate activity results. Therefore, we collected documents from the POAM analysis activity performed in A Hospital, and constructed an evaluation standard list to evaluate them.

First, we grasped contents of the POAM analysis activity through an investigation of an impeller activity. Next, we went into detail about the activity contents from the viewpoint of standard enforcement procedures and derived the arrival target of each enforcement procedure based on the argument with the POAM teacher as a check item. The results are shown in Table 5.

Table 5. Evaluation standard list of the POAM analysis activity (part A)

\begin{tabular}{|c|c|c|c|}
\hline Process of the activity & Evaluation items & Check item & No. \\
\hline \multirow{2}{*}{$\begin{array}{l}\text { Choice of the accident } \\
\text { report }\end{array}$} & \multirow{2}{*}{$\begin{array}{l}\text { Whether they choose } \\
\text { an example suitable } \\
\text { for POAM analysis or } \\
\text { not }\end{array}$} & $\begin{array}{l}\text { Whether they choose the example of the process } \\
\text { type instead of a non-process type }\end{array}$ & $(1)$ \\
\hline & & $\begin{array}{l}\text { Is it written in accordance with the standard in the } \\
\text { stage of the instructions tray, preparation, and } \\
\text { enforcement? }\end{array}$ & $(2)$ \\
\hline$\ldots$ & $\ldots$ & $\ldots$ & \\
\hline \multirow[t]{2}{*}{ Drafting of measures } & \multirow{2}{*}{$\begin{array}{l}\text { Whether they can } \\
\text { perform measure } \\
\text { drafting or not }\end{array}$} & $\begin{array}{l}\text { As for the measures, is it written about a process, } \\
\text { such as standardization and error proofing? }\end{array}$ & $(20)$ \\
\hline & & Are the measures written in detail? & $(21)$ \\
\hline
\end{tabular}


Evaluation for Healthcare-Safety-Education, Goto et al.

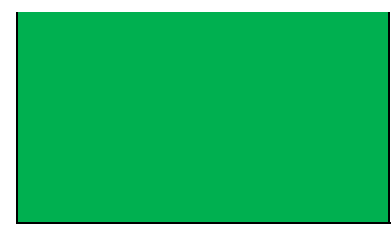

Can the measures solve the problem that they gave in the factor analysis?

Are the measures to be carried out decided under the agreement of all members?

We set a marking standard of some check items to raise the objectivity of the evaluation. For example, for item (21), if measures were not written along $4 \mathrm{~W} 1 \mathrm{H}$, zero points were given. Therefore, we could evaluate the utilization situation without depending on the evaluator.

\section{A suggested method to evaluate the effectiveness of medical safety education}

Based on the findings of this study, we suggest a method to evaluate the effectiveness of medical safety education.

Step 1: Grasp of the present state of the will of the student for the education contents

We constructed evaluation items for the medical care safety education based on the guidance of the education target classification of Marzano. The first questionnaire survey was designed based on those evaluation items.

We then conducted the questionnaire survey including the item about the consciousness of the effectiveness, importance, and the state of feelings before education.

Step 2: The measurement of the degree of understanding of student knowledge

We designed the degree of understanding investigation using the construction method suggested by Goto and others, and carried it out after education. We conducted an investigation regularly in order to observe the degree of knowledge acquisition and the skill of the student attending a lecture in chronological order.

Step 3: Measurement of the influence of the education contents on the spot

$3-1$ : We carried out the second questionnaire survey after education.

$3-2$ : We constructed an evaluation standard list based on the activity process on spot.

3-3: We conducted an evaluation by the evaluation standard list and the questionnaire survey

regularly to evaluate changes in the utilization situation.

This method allows for the evaluation of the degree of action transformation, as well as the degree of knowledge acquisition and skill in the student attending a lecture.

\section{Examining the effectiveness of the goal}

\subsection{Examining the effectiveness of items in the questionnaire}

To examine the effectiveness of the investigation on the goal, as explained in Section 3.2.3, I conducted a survey on 15 members of the accident analysis team of Hospital A, using a questionnaire. The accident analysis team utilized the POAM to analyze a real accident example from the previous year and drafted rules for the ward. In addition, in this section, we also present the findings of the interview of the manager of the team and inspect the effectiveness of the contents of the evaluation.

Subjects of survey: 14 link nurses of Hospital A and 30 nurses of the X-disease ridge.

Investigation from: Questionnaire survey

The completed questionnaires were received from all the link nurses (100\%) and $63 \%$ of the nurses of the X-disease ridge. They rated each item on a five-point scale, specifically, "not applicable," "applicable to some extent," "was not which," "largely applicable," and "totally applicable.” Their responses were scored from one to five, respectively, and means were calculated. The related findings are presented in Table 5. It is also important to note that a link nurse and a nurse of the X-disease ridge worked together on the analysis of the POAM, for one year. 
Total Quality Science Vol.1, No.1

Table 6. Mean on each item of the questionnaire

\begin{tabular}{|c|c|c|c|c|c|c|c|c|c|c|c|c|c|}
\hline & Q 1 & Q 2 & Q 3 & Q 4 & Q 5 & Q 6 & Q 7 & Q 8 & Q 9 & Q 10 & Q 11 & Q 12 & Q 13 \\
\hline $\begin{array}{c}\text { Link nurses } \\
\text { X-disease ridge } \\
\text { nurses }\end{array}$ & 4.36 & 2.50 & 3.86 & 3.21 & 2.79 & 2.57 & 2.86 & 2.62 & 3.08 & 2.64 & 2.71 & 2.57 & 3.36 \\
\hline
\end{tabular}

It can be observed from Table 6 that a low rating, specifically, that below three points, was predominant, with very few items depicting a score of four points or above. Specifically, both, link nurses as well as X-disease ridge nurses exhibited a higher score on Q1, which was related to the importance of the POAM. Thus, the acknowledgement of the importance of conducting an accident analysis seems to be apparent. On the other hand, with reference to Q3, on the awareness of the weak points of the POAM, the rating of the X-disease ridge nurses was particularly high.

Then, based on the responses of the link nurses and the nurses of the X-disease ridge, we performed a correlation analysis to examine the relationship between the items of the questionnaire. These results are presented in Table 7.

Table 7. Correlation analysis on the items of the questionnaire

\begin{tabular}{|l|c|c|c|c|c|c|c|c|c|c|c|c|c|}
\hline & Q1 & Q2 & Q3 & Q4 & Q5 & Q6 & Q7 & Q8 & Q9 & Q10 & Q11 & Q12 & Q13 \\
\hline Q1 & & & & & & & & & & & & & \\
\hline Q2 & 0.068 & & & & & & & & & & & & \\
\hline Q3 & -0.220 & -0.304 & & & & & & & & & & & \\
\hline Q4 & -0.052 & 0.028 & -0.293 & & & & & & & & & & \\
\hline Q5 & -0.142 & 0.210 & -0.122 & 0.251 & & & & & & & & & \\
\hline Q6 & -0.128 & 0.302 & -0.215 & 0.188 & 0.739 & & & & & & & & \\
\hline Q7 & -0.020 & 0.314 & -0.393 & 0.190 & 0.653 & 0.442 & & & & & & & \\
\hline Q8 & 0.054 & 0.269 & -0.250 & 0.364 & 0.439 & 0.446 & 0.352 & & & & & & \\
\hline Q9 & 0.107 & 0.205 & 0.018 & 0.167 & 0.296 & 0.317 & 0.204 & 0.370 & & & & & \\
\hline Q10 & 0.328 & 0.189 & -0.243 & -0.157 & 0.293 & 0.207 & 0.346 & 0.265 & 0.335 & & & & \\
\hline Q11 & 0.010 & 0.323 & -0.429 & 0.003 & 0.391 & 0.475 & 0.362 & 0.327 & 0.188 & 0.449 & & & \\
\hline Q12 & 0.187 & 0.137 & -0.559 & 0.035 & 0.152 & 0.286 & 0.282 & 0.235 & 0.092 & 0.517 & 0.591 & & \\
\hline Q13 & 0.082 & 0.116 & -0.506 & 0.276 & 0.037 & 0.191 & 0.217 & -0.199 & -0.094 & 0.063 & 0.151 & 0.330 & \\
\hline
\end{tabular}

With reference to Table 7, the following a point need to be noted:

-The correlation between the items on the influence of education contents on the understanding (Q 11-13) and the item on weak point awareness (Q3) (this section is highlighted in green in the table).

With reference to this point, it is thought that "the weak point awareness" influences the understanding at the processing level, specifically, in the autonomous system (the system that closely examines will). In other words, it is thought that if an individual has a strong awareness of her weakness for POAM, it will be difficult for her to understand the POAM, and to utilize it onsite.

When the manager of Hospital A was questioned about the cause of the weak point awareness, she reported that it may be influenced by the lack of power to think things by a process, which is characteristic of nursing education, and to solve a problem. We knew that in the nursing school, there were few opportunities to understand why things are taught the way they were. With reference to the POAM, the students learnt the procedure of analysis even if they did not know its purpose. Owing to this, it is thought that thinking about things by a process is difficult for them such as POAM investigating a thing without the correct answer.We agreed with the manager on this aspect.

\subsection{Inspection of the general purpose of the suggested method}

We applied the suggested method to the training of KYT carried out in B Hospital. In the training, the purpose was for students to acquire the ability to practice KYT on site. The subjects of the evaluation using the suggestion method were 13 safety managers and some students attending KYT lectures who had learned KYT. In the evaluation, we administered a questionnaire survey before and after the training, and conducted an 
evaluation of the influence of education contents using an evaluation standard list. We also conducted a degree of understanding investigation composed of 10 questions ( 2 points per question) immediately after the training. The questionnaire findings and the result of the degree of understanding investigation are shown in Figures 4 and 5.

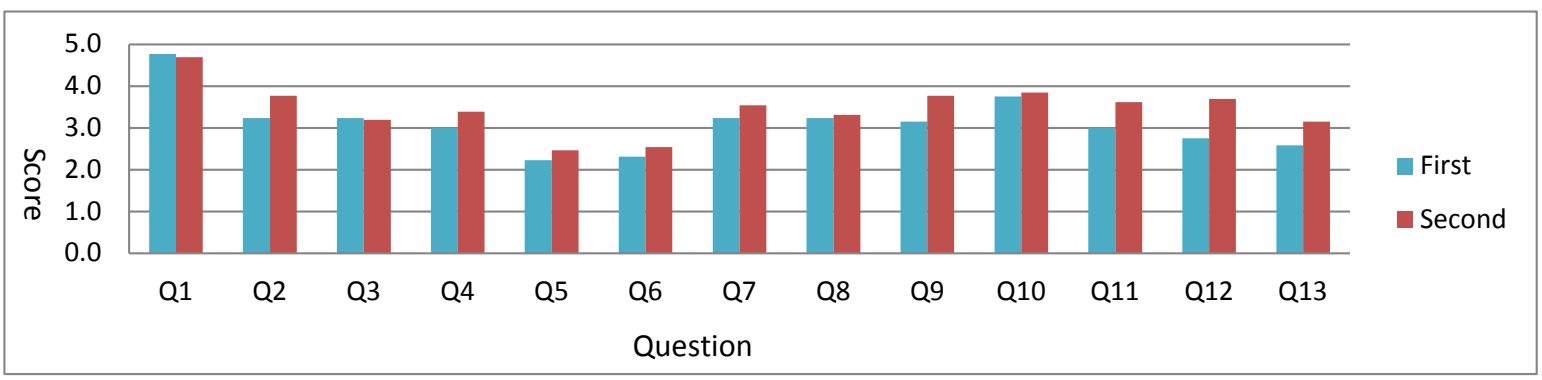

Figure 4. Questionnaire findings before and after the training

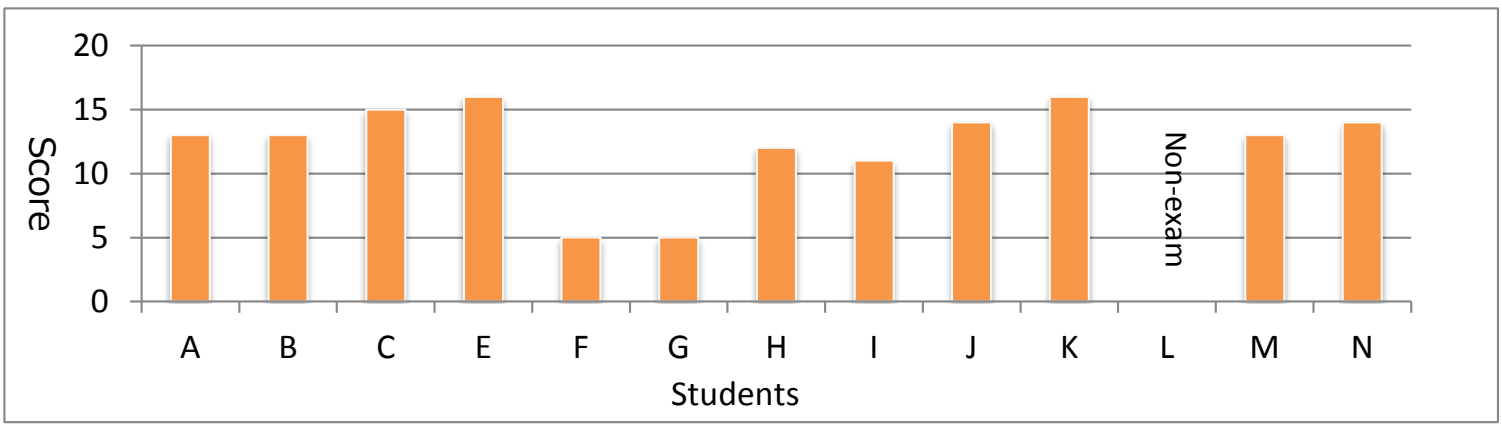

Figure 5. Results of the degree of understanding investigation

Figure 4 demonstrates an improvement trend in the questionnaire results in most items after the training. Further, from the degree of understanding investigation, we were able to distinguish students with low scores from those with high marks. In addition, regarding the scores of the evaluation standard list, 19 points indicated a perfect score, and the average score increased from 10.5 points (standard deviation: 2.32) before the training to 13.3 points (standard deviation: 3.86 ) after the training.

Regarding these results, three students who had high scores in understanding the investigation, the evaluation standard list, the item about students' will for education may be able to best utilize the education contents.

Accordingly, we compared these with the questionnaire results of three students who enforced the knowledge in a medical safety promotion room of B Hospital after the training. These students reported changes in on-site action: "The critical eye for danger improved, and knowledge was deepened as a function of KYT, and I was able to teach it to a younger student" and "I divided it into teams and taught KYT and was able to publicize it." Therefore, it was suggested that, if the will of the student to attend lectures improves after the training, the degree of the influence of KYT rises. We were then able to apply a suggestion method to measure the effect of KYT training.

\section{Contributions of the study}

Previous studies used conventional methods to evaluate the degree of acquisition of knowledge and skills. Additionally, there was no method to evaluate the degree of transformation of actions of the student attending a lecture after the completion of the program. In this study, we focused on the influence of education on the change of consciousness in the student attending a lecture and derived the goal of the transformation of action by using an action model. We also suggested a method to evaluate the degree of transformation of action by regularly measuring the same after the education. Previous studies on the measurement of the effectiveness of education did not demonstrate the process of deriving a goal of examining the degree of transformation of action. To identify the goal in this study, we utilized a framework of the education target taxonomy used in the action model; therefore, we could explain it in detail. 


\section{Conclusion and future research}

In this study, we examined a method to evaluate the degree of transformation of action after education, in addition to a method to measure the knowledge of the student attending a lecture and the degree of acquisition of a skill, and suggested a method to evaluate the effectiveness of medical safety education. Future studies can explore the utility of the suggested method in evaluating other educational programs.

\section{References:}

Uichi Tsutsumi et al. (2007),"First education effect measurement”,Nikkagiren Shuppansya.

Human Value (2004),”ASTD2004 report” at http://www.humanvalue.co.jp/astd/astd2004rep/

Jack Philips (1999),"Education training effect measurement handbook,” Efficiency Management Center, Japan.

Robert Brinkerhoff (2009),"'The success case method:find out quickly what's working and what's not”,Brett Koehler Publishers.

Chisaato Kajihara et al. (2012),“Proposal of educational contents for healthcare Safety” ,Quality,vol.42[3],pp. 106-117.

Japanese Nursing Assosiation (2013),“Standard text for medical safe promotion”,Nonprofit Foundation Japan Nursing association.

Makiko Takahashi (2014),“'Improve the skill that the school teacher teaches with a learner by simulation education”, Nursing business vol.8(12),pp.1122-1125.

Futoshi Ebara (2014),“Raise awareness of security and prevent an error, by visualizing a characteristic by a safe action investigation and setting goal that fitted each person,” Nursing business vol.8(12),pp.1134-1138.

Toshihiko Takemura (2011), “Study on changes in medical safety awareness-comparison of time series changes in Japanese national university hospital”,Japan Society for Healthcare Administration.

Kyoko Inaga (2007),“Measurement methods of effect for education for prevention of medical accident” Kitakyusyu Municipal University,(21),pp.145-166.

Takeyuki Goto et al. (2013),“A study on the measurement method of effect for healthcare safety education,” The 11th ANQ Congress,pp.210.

Masataka Sano at el . (2013),“Analysis of medication Incident for Improvement of medication process”, Total Quality Management \& Business Excellence.

Chisato Kajihara et al. (2011), “A proposal of designing method of Kiken Yochi Training sheets in Medication Incidents”,Quality,vol.41(3),pp.361-370,JSQC.

Robert Marzano, John Kendall (2013),“Designs educational objectives”, The Kitaoji bookshop.

\section{Author's biographical notes}

Takeyuki Goto is a student who is the second year of the master's program of Waseda University and he studies management design. In 2013, he graduated from Waseda University. He made the study on Education for Healthcare Safety. He is a member of the Japanese Society for Quality Control (JSQC).

Masahiko Munechika is a professor in department of industrial and management system engineering, school of creative science and engineering, Waseda University from 2007. His research has focused on quality management and statistical analysis, including TQM, sentiment quality, healthcare quality, and management diagnosis. He is also a member of Deming Application Prize Committee and Japanese delegate of ISO/TC176.

Chisato Kajihara is a research associate of Creative Science and Engineering, Waseda University, Tokyo, Japan. She earned Doctor of Management Engineering in 2013. Her research has focused on Quality Management System (QMS) and Business Continuity Management System (BCMS).

[DOI : 10.17929/tqs.1.41]

Received, May 20, 2014

Revised: November 11, 2014

Accepted: February 27, 2015 